\title{
Effects of the Intercultural Exchange on the Life of International Students in Wuhan (China)
}

\author{
Sékou Amadou Traore, Sinaly Diarra \\ Central China Normal University (CCNU), Wuhan, China \\ Email: sekamtra1@yahoo.fr, diarrasinaly50@gmail.com
}

How to cite this paper: Traore, S. A., \& Diarra, S. (2019). Effects of the Intercultural Exchange on the Life of International Students in Wuhan (China). Advances in Applied Sociology, 9, 243-257. https://doi.org/10.4236/aasoci.2019.97019

Received: May 29, 2019

Accepted: July 5, 2019

Published: July 8, 2019

Copyright () 2019 by author(s) and Scientific Research Publishing Inc. This work is licensed under the Creative Commons Attribution International License (CC BY 4.0).

http://creativecommons.org/licenses/by/4.0/ (c) (i) Open Access

\begin{abstract}
As it is recognized that the number of the foreign students is increasingly becoming more and more important around the world, which needs to be regarded in the context of sociology and psychology, because some person has a difficulty to adapt themselves to the new place. Nowadays, China is considered to be one of the famous countries, which is expected by many students to continue their study, but most of these students have not the same ability to satisfy emotional hole due to the social status. So, in order to determine this problem, this study used some sociopsychological variables based on the plan of the Likert scale with 5 points which included the questionnaire to understand the effect of sociodemographic factors on the change of emotional character, and behavior of foreign students in Wuhan-China. Besides, 42 participants shared between the three universities of Wuhan have answered the questions, and the data gathered through this instrument will be statistically analyzed with the help of Software Package for Social Sciences (SPSS). As the result, this study proposed that with difference in age, in marital status, in duration to stay abroad, people cannot have the same manner to feel themselves in the new place. Therefore, for more contribution to the same issue a new research can be conducted by including interview and open-ending questions and focusing on the person of different ages in order to bounce out which group of age can be comfortable to study abroad.
\end{abstract}

\section{Keywords}

Emotive Character, Behavior, International Students, Intercultural Exchange, China

\section{Introduction}

China, like many countries of Europe, attracts more and more students from 
different nationals of all continents in the world who wish to deepen their knowledge in Chinese universities. They find themselves facing administrative difficulties (residence permit), financial (lack of scholarships), sociocultural (adaptation to the host country, social network) that hinder their training process, but especially their social and psychological life. Thus, the need for humans to react quickly to change, to adapt and to learn from the experience of new society or culture became imperative in the 1990s. As a result, this change is a response to economic pressure, to the changing needs of businesses, to demographic changes, dynamics, social organizational and technological changes (Kakabadse, Korac-Kakabadse, \& Kouzmin, 1998).

Moreover, human self-regulatory emotion has always been a big problem when human is across the new situation or place as argued. There are many models for how to regulate emotion, immediate emotion reactions are what they are caused by evolutionary or biological reactions and are neither intelligent or unintelligent. But the interplay between the individual's cognitively more developed construction and regulation of emotion, on the one hand, and beliefs about emotion, on the other hand, can be more or less intelligent (Mayer \& Gaschke, 1988).

According to Mayer \& Gaschke (1988), although emotion-regulatory activities occupy only a modest part of personality function as a whole, they nonetheless form too large a topic to consider all together. For this reason, emotional regulation is divided into subcategories according to the levels of awareness or conscious they involve. So, in the self-emotional regulatory the dimension of consciousness is important because qualitative differences emerge in emotional responses according to the amount of conscious attention available to those reactions; greater complexity and creativity of responses are possible where attention is prolonged (Mayer \& Salovey, 1995).

Beside, some more effects of new circumstance reliability for individual can be his/her looking for how to strengthen his or her own character (Nansook, Peterson, \& Seligman, 2004). It notes that the character development should be based on the capture of the family collaged without the rejection of others but rather their acceptance. In this context, international students living in Wuhan can undergo these psychological gymnastics which can determine the content of their character. Change of living space and more affects the nature of human character. This has been addressed in different ways by psychologists (Nansook, Peterson, \& Seligman, 2004). According to him, although the religion is an important factor in the change of character, the direction of the future has a socio-economic connotation. In this same dynamic, the link between social outcome, health and social adjustment balances widely. It seems likely that any effort to predict variation in outcome or adjustment after some disease analysis would involve the use of both psychosocial and physiological indices as predictors. Evidence derived from other situations that involve potentially disabling physical trauma suggests that such indices are related to variation in outcome (Shontz \& Fink, 1961). It is clear that income is an indicator important overall 
recovery of sociodemographic factors, physiological and psychological of the individual (Zheutlin \& Goldstein, 1977).

Furthermore, Consistent with the importance of personal growth in promoting mental health in adults, it bounces that personal growth is associated with a wide range of important psychological outcomes (e.g., psychological well-being, optimism, positive affectivity, psychological distress, depression, anxiety; Frazier \& Kaler, 2006; Luke \& Kiweewa, 2010; Moran, Burker, \& Schmidt, 2013; Park, 2004; Park, Cohen, \& Murch, 1996; Shorey, Little, Snyder, Kluck, \& Robitschek, 2007; Tedeschi \& Calhoun, 2004).

In addition, travel abroad has been said to be a way to increase creativity. Gurman has pointed out a commonality shared by creative people: they have experienced diversity: "a wide variety of experiences, often dating back to childhood" (1989, p. 12). He argues that it is the exposure to novel situations which stimulates the creative process (p. 12). Therefore, travel abroad should provide the perfect novel situation to stimulate creativity. Nolan Bushnell, founder of the Atari Corporation, agrees, adding that many of his best ideas arose through traveling (Shumate-Fowler, 1995). Then, here are theorists' explanation about emotion and emotional contagion. Let us begin by defining emotion. Emotion differs from attention and memory in that, minimally, emotional stimuli: 1) are categorized as being either positive or negative, and 2) predispose people to bivalent behavior (e.g., approach or withdrawal toward the stimuli. Some focus on the disagreement between the constituents of the family emotion (Ekman, 1992; Izard, 1992; Ortony \& Turner, 1990; 1995; Panksepp, 1986; Papez, 1937).

Recent theorists have moved away from linear, undeterministic reasoning and have decided, instead, that "it depends": emotional stimuli may well trigger the conversant awareness, somatovisceral, and behavioral aspects of emotion almost simultaneously; which appears first depends on the person and the situation. Thus, theorists are increasingly asking how each of the emotional components acts on and is acted upon by the others (Berscheid, 1983; Candland, 1977; Carlson \& Hatfield, 1992). According to Hatfield et al. (1994), Emotional contagion is best conceptualized as a multiply determined family psychophysiological, behavioral, and social phenomena. Because, emotional contagion can be produced by innate stimulus features (e.g., a mother's nurturing expressions and actions toward an infant), acquired stimulus features, and/or mental simulations or emotional imagery.

This article is based on the results of a research conducted among the students coming from different continents to Wuhan-China which goal was to analyze the effects of cultural exchange on the lives of foreign students in Wuhan-China. As a result, it is intended in particular to understand the effect of sociodemographic factors on the change of emotional character, and behavior of foreign students in Wuhan-China. This province is considered to be a university town, which offers training and service in all major areas. Adaptation to new society or culture remains a relevant concern in the world. Indeed, it is assumed that 
people have the same ways to be affected by the events in new sociocultural situation. So the assumption in this article is that sociodemographic factors have impacts on the nature of the emotional and behavioral of the individual in another environment different from its original one.

\section{Methodology and Instrument of Measurement}

This study is empirical. It relies exclusively on quantitative method. In this context, the different factors formed the basis of analysis and the quantitative approach has been used to analyze the data collected from foreign students living in Wuhan (China). To do this, we used SPSS version 23 to assess the different variables to a correct interpretation of the sociopsychological effects of intercultural exchanges on the lives of foreign students in Wuhan-China. This has allowed us to analyze descriptive and inferential. Initially, the descriptive analysis concerned the mean and standard deviation, which has to show a good accuracy on variables more or less effects on the lives of foreign students in China. Secondly, the inferential based on correlation and regression analysis, more to understand the significant links between variables that may explain the intercultural exchange effects on the life of foreign students living in Wuhan (China). Measuring instrument was the questionnaire. This helped to collect data relating to the objectives of the "study". It featured sociodemographic variables where indicators are related (age, gender, status marriage, continent of origin, level of study, nature of scholarship, duration in Wuhan). In addition, sociopsychological variables based on the plan of the Likert scale 5-points were included in the questionnaire: rarely or none of the time 1), some or a little of the time 2), occasionally or a moderate amount of the time 3), most or generally of the time 4), and every or all of the time 5). Then, the range is divided with different variables on emotional character and behavior that can probably be affected during the intercultural exchange. It compounded 9 items of emotional character, divided into 3 parts to the test: test of emotive character, active character test and test of primary character; and 9 items on the emotional behavior, divided into 3 parts emotive behavior an active behavior and primary behavior.

\section{Procedure:}

This study has been conducted among three universities in Wuhan: Central China Normal University (CCNU), Wuhan University, And Zhongnan University of Economics and Law. In the process of data collection, self-administered questionnaires have been distributed among 42 participants in these different universities. The participants have completed the questionnaire under the convenient time to the instructors. In order to select the participants, we consulted some of our country-mates and friends in these different Universities, because this way is one of the simple to attain the international students at the Universities in Wuhan. Through, them our participants have been accessible and distributed the questionnaires by taking into account the time-table of participants and the fixing data confirmed by researchers. 


\section{Results of Study}

\subsection{Frequency Result}

Analysis shows a total of 42 participants shared between the three universities. Among these participants, according to the gender $64.3 \%$ men against $35.5 \%$ women. At the level of the variable age, on a total of 16 respondents, $50 \%$ are included in the age group of 17 - 25-year-old, $43.8 \%$ are the age group of 26 35 -year-old and $6 \%$ are included in the age group of 36 - 45-year-old. Of 42 respondents, $21.4 \%$ were married against $78.6 \%$ unmarried. For the variable religion it appears that level of the 41 respondents, $23.8 \%$ Muslims, $40.5 \%$ Christians, $2.4 \%$ animist, $23.8 \%$ others religion, $7.1 \%$ for no-religion.

Moreover, in this study 41 students of different levels have answered: bachelor: $13=31.0 \%$, master: $15=35.7 \%$, PhD: $9=21.4 \%$, other: $4=9.5 \%$. And most of the 42 test takers were Africans: $40.5 \%$, Asian: $33.3 \%$, European: $19.0 \%$, and American: $7.1 \%$. Then, the 34 participants' duration of staying in China are different from $0-2$ years $=31.0 \% ; 3-5$ years $=35.7 \% ; 6-8$ years $=11.9 \% ; 9-11$ years $=2.4 \%$. Besides, $52 \%$ of these 42 students were covered by full scholarship program; $11.9 \%$ were covered by partial scholarship program; but $35.7 \%$ were self-supporting students. Furthermore, the taught program concerned among the 39 observed students compounded 52.4\% in English program, 31.0\% in Chinese program, and other $9.5 \%$. And then, $52 \%$ among these 42 participants have already experienced to travel abroad before coming in China; but $47.6 \%$ had no experience before. So, in the context of culture $52.4 \%$ of these 42 students showed no similarity between the culture; $31.0 \%$ proved somehow similarity; $14.3 \%$ approved it is moderately similar; and $2.4 \%$ agreed that there is a great similarity (see Table 1 Socio-demographic Frequency, and Table 2 shows the figures of frequency distribution of gender, age, marital status, religion, study level, and continent).

\subsection{Descriptive Result}

This research proved that the emotional state was disequilibrium such as, active character was higher with the mean $=10.2$ and standard deviation $=2.98$; then followed by primary character, mean $=9.87$ and standard deviation $=2.17$; successively, emotive behavior which has the mean $=9.24$ and standard deviation $=$ 2.48. Besides, it bounced also active behavior is considerable with the mean = 9.05 and standard deviation $=2.90$; it keeps behind primary behavior, mean $=$ 8.76 and standard deviation $=2.87$; finally, the emotive character with the mean $=6.73$ and the standard deviation $=2.46$ (See Table 3 Descriptive statistics).

\subsection{Exploratory Result}

So comparing men and women in the active character level, the result determined that the number of men with high active character are larger than women $(\mathrm{M}=1.33, \mathrm{SD}=.52), p<.001$. But in primary character, the women have the highest level than men $(\mathrm{M}=1.63, \mathrm{SD}=.52), p<.000$. Then, for emotive 
Table 1. Frequency of socio-demographic.

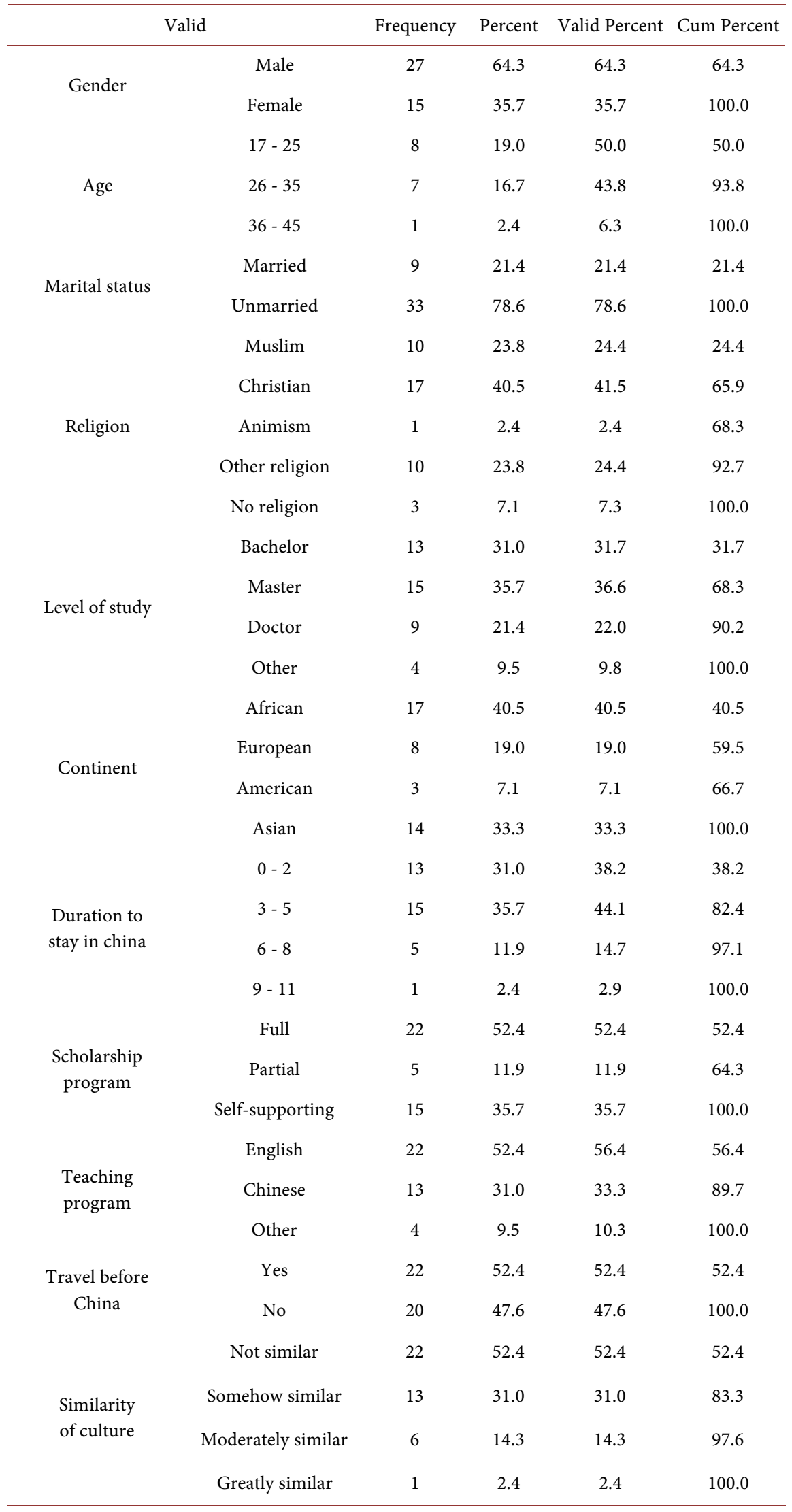


Table 2. Histogram of frequency validity.

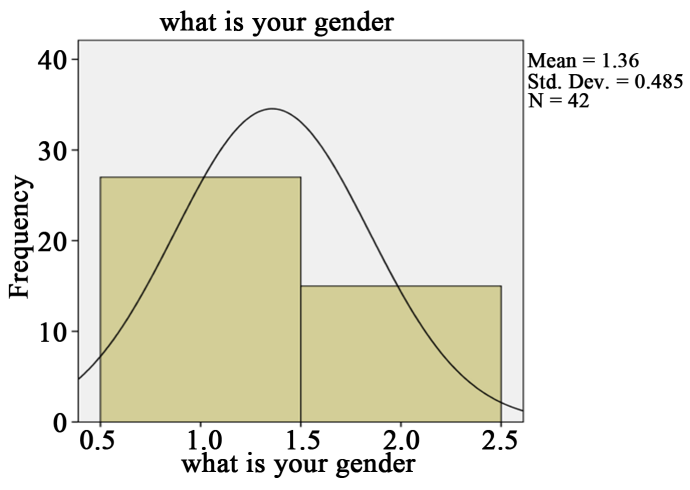

The frequency validity of gender

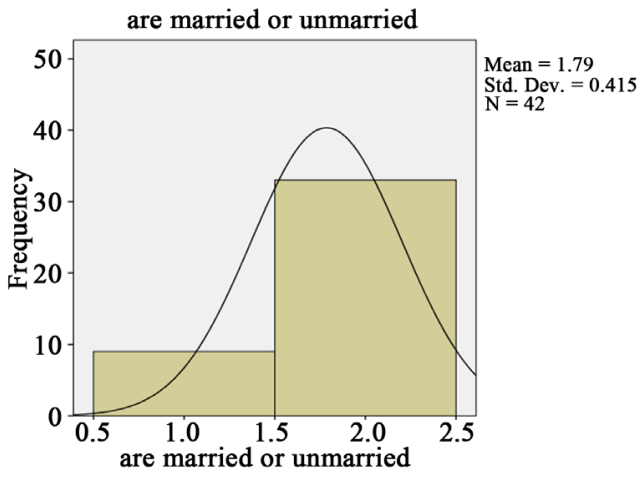

The marital status
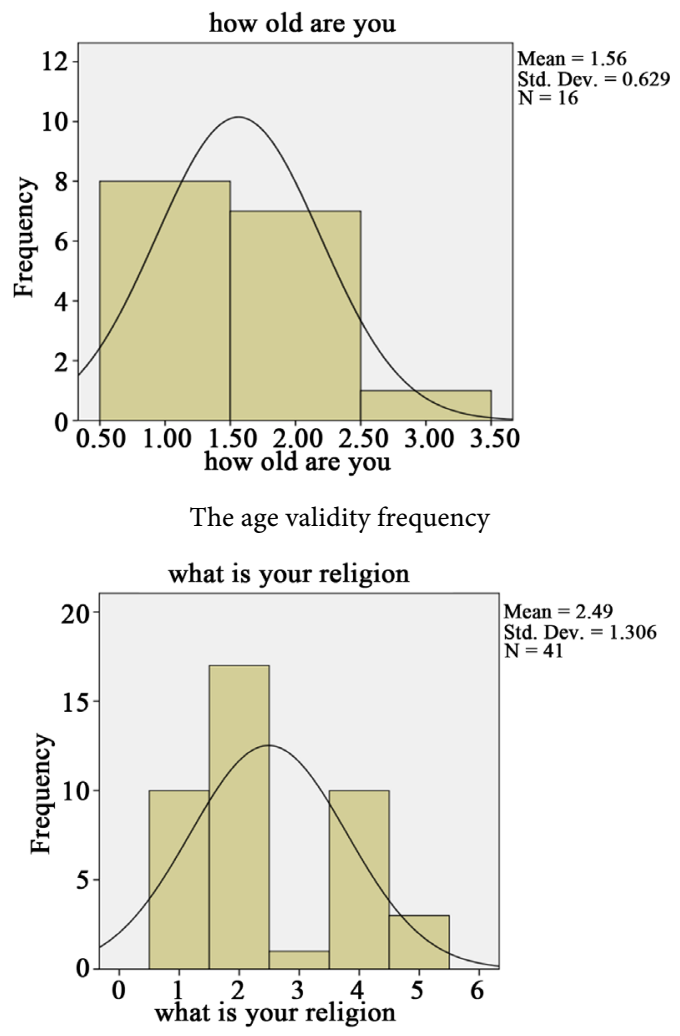

what is your level

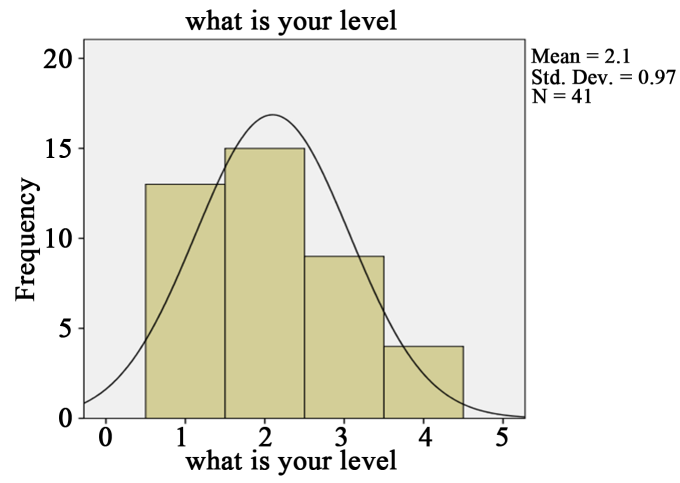

Concerns study level

religion

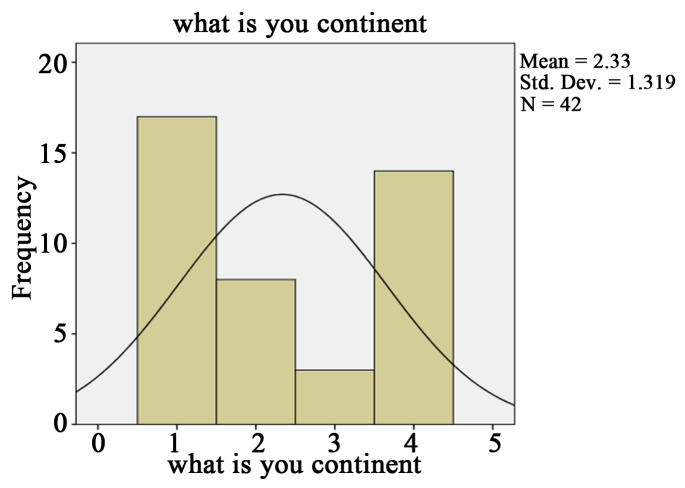

The frequency validity of continent

Table 3. Descriptive statistics.

\begin{tabular}{cccc}
\hline & N & Mean & Std. Deviation \\
\hline Emotive character & 37 & 6.73 & 2.46 \\
Active character & 39 & 10.03 & 9.87 \\
Primary character & 38 & 9.05 & 2.17 \\
Active behavior & 41 & 9.24 & 2.89 \\
Emotive behavior & 37 & 8.76 & 2.48 \\
Primary behavior & 41 & & 2.87 \\
Valid N (list wise) & 33 & & \\
\hline
\end{tabular}


behavior the number of men is higher in the highest level than women $(\mathrm{M}=$ $1.22, \mathrm{SD}=.44), p<.000$. significantly at the part of active behavior men are more active than women $(\mathrm{M}=1.25, \mathrm{SD}=.5), p<.001$. Contrary to men, women possess the highest primary behavior $(\mathrm{M}=1.63, \mathrm{SD}=.62), p<.000$; similar in emotive character $(\mathrm{M}=1.8, \mathrm{SD}=.44), p<.001$.

Respectively, the emotional state varied through the different ages. In active character stage the age group of 17 - 25-year-old have more considerable level than others $(\mathrm{M}=1.33, \mathrm{SD}=.58), p<.000$. But the age group of $26-35$ year-old have lower emotional character than other groups $(\mathrm{M}=1.67, \mathrm{SD}=.58), p<.000$. Moreover, at the emotive behavior the age group of 17 - 25-year-old are behaving more emotively $(\mathrm{M}=1.33, \mathrm{SD}=.58), p<.000$. then in the level of active behavior of the age group of $36-45$ year-old have the lower level than other $(\mathrm{M}=$ $1.75, \mathrm{SD}=.95), p<.27$. Therefore, the age group of $17-25$-year-old and $26-35$ year-old have higher primary behavior level than the age group of $36-45$ year-old $(\mathrm{M}=1.80, \mathrm{SD}=.83), p<.20$. Yet, for emotive character, the age group of 17 - 25-year-old have higher level than other groups $(\mathrm{M}=1.33, \mathrm{SD}=.58), p$ $<.000$

Moreover, regarding the emotional state and the marital status of participants it is recognized that married students have high frequency at the low level than unmarried $(\mathrm{M}=1.25, \mathrm{SD}=.5), p<.001$; similarly, for primary character $(\mathrm{M}=$ $1.75, \mathrm{SD}=.5), p<.5$; and emotive behavior $(\mathrm{M}=1.88, \mathrm{SD}=.35), p<.000$. Besides, we discovered the highest level of active behavior at the side of unmarried than married $(\mathrm{M}=1.8, \mathrm{SD}=.44), p<.001$. Similar to primary behavior $(\mathrm{M}=$ $1.88, \mathrm{SD}=.34), p<.000$; and emotive behavior $(\mathrm{M}=1.88, \mathrm{SD}=.54), p<.000$.

Besides, in the context of religion this study found that the students in other religion have low active character than other students $(\mathrm{M}=3.33, \mathrm{SD}=.58), p$ $<.000$. But the Muslims have more primary character than others $(\mathrm{M}=1.24, \mathrm{SD}$ $=.5), p<.001$; in contrast, at emotive behavior Christians are perceived to be high $(\mathrm{M}=2.11, \mathrm{SD}=1.17), p<.01$; and they have high level of active behavior $(\mathrm{M}=1.67, \mathrm{SD}=.58), p<.000$. Considerably, in primary behavior it is found that the Christians and students in other religion are overlapped at low level $(\mathrm{M}=3$, $\mathrm{SD}=1.41), p<.100$. Therefore, for emotive character it saw that Christian have high level, and it is followed by no religious $(\mathrm{M}=3.2, \mathrm{SD}=1.64), p<.006$.

Furthermore, through this study more African students have higher level of emotional active character than the students from other continent $(\mathrm{M}=2.17, \mathrm{SD}$ $=1.47), p<.02$; and higher level of primary character $(\mathrm{M}=1.75, \mathrm{SD}=1.5), p$ $<.001$. Besides, at the level of emotive behavior Africans' number at highest is considerable than others $(\mathrm{M}=2.11, \mathrm{SD}=1.45), p<.001$. But, for active behavior the Asians have larger number at low level $(\mathrm{M}=3.33$, $\mathrm{SD}=1.16), p<.000$; similarly, at primary behavior $(\mathrm{M}=3.33, \mathrm{SD}=1.16), p<.000$. Then, in the emotive character, most of the European have higher level than others $(\mathrm{M}=2.2, \mathrm{SD}=$ $1.09), p<.02$.

Indeed, regarding the different levels of education the result constantly noted that more students at Master degree and $\mathrm{PhD}$ degree showed low active charac- 
ter than bachelor's students $(\mathrm{M}=2.25, \mathrm{SD}=.58), p<.02$. But, according to this explorative result, Bachelors and Masters have larger frequencies at the highest level of primary character than $\mathrm{PhD}$ students $(\mathrm{M}=1.75, \mathrm{SD}=1.03) p<.007$; this is the same for emotive behavior $(\mathrm{M}=1.67, \mathrm{SD}=.70), p<.02$. Distinguishably, Master's students have the highest level at active behavior than others $(M=2$, $\mathrm{SD}=.70), p<.16$; contrary, in primary behavior they have low level $(\mathrm{M}=2.67$, $\mathrm{SD}=1.15), p<.000$. Then, more Master's students approved at the highest side of emotive character $(\mathrm{M}=1.8, \mathrm{SD}=.44), p<.000$.

Continuously, it is recognized by this study that students who stay from 0 to 2 years, and 3 to 5 years have high level in active character than who stay for longer duration $(\mathrm{M}=1.67, \mathrm{SD}=.70), p<.02$; seemingly, to the primary character $(\mathrm{M}$ $=1.50, \mathrm{SD}=.53), p<.001$. They behave more emotively than others $(\mathrm{M}=1.78$, $\mathrm{SD}=.97), p<.006$. Considerably, for active behavior, students who stay from 0 to 2 years have higher level than others $(\mathrm{M}=1.60, \mathrm{SD}=.89) p<.04$. In contrast, at the level of primary behavior students who stay from 3 to 5 years proved higher state $(\mathrm{M}=2.25, \mathrm{SD}=.88), p<.003$. But, students who stay from 0 to 2 years have higher level than others in emotive character $(\mathrm{M}=1.20, \mathrm{SD}=.44), p$ $<.001$.

Measuring students' emotional state through their scholarship program, we contacted that students who are covered by full scholarship have higher level of active character than other kinds of scholarship $(\mathrm{M}=1.67, \mathrm{SD}=1.03), p<.001$; and more primary character $(\mathrm{M}=1.5, \mathrm{SD}=.92), p<.000$. Similarly, they have high level in emotive behavior $(\mathrm{M}=1.89, \mathrm{SD}=1.05), p<.000$; even in active behavior they have more frequency than others $(\mathrm{M}=1.5, \mathrm{SD}=.1), p<.001$. Then, in primary behavior students self-supporting have larger number at lowest level than others $(\mathrm{M}=2.5, \mathrm{SD}=1), p<.001$. But, this result proved that self-supporting students have higher level in emotive character $(\mathrm{M}=2.2, \mathrm{SD}=$ $1.09), p<.006$.

Therefore, analyzing the teaching program of the students we perceived that students who are taking their major's classes in English are more frequent at the high level of active character than students at the Chinese taught program $(\mathrm{M}=$ $1.33, \mathrm{SD}=.51), p<.001$. But, for primary character students at the Chinese taught program have higher level than English one $(\mathrm{M}=1.63, \mathrm{SD}=.51), p$ $<.001$. Nevertheless, English taught program students showed high level in emotive behavior $(\mathrm{M}=1.11, \mathrm{SD}=.33), p<.000$; and active behavior $(\mathrm{M}=1.2, \mathrm{SD}$ $=.44), p<.000$. In contrast, for primary behavior students at the Chinese taught program have higher level $(\mathrm{M}=1.63, \mathrm{SD}=.51), p<.001$; but lower level in emotive character $(\mathrm{M}=1.67, \mathrm{SD}=.57), p<.000$.

After exploring the travel experience an emotional state it is perceived that students who traveled before coming in China showed greater frequency at the higher state of active character than no experimented students $(\mathrm{M}=1.33$, SD $=.51), p<.002$. Yet, in primary character no experimented students have higher level $(\mathrm{M}=1.75, \mathrm{SD}=.5), p<.001$. Contrary, in emotive behavior experimented students have high level than no experimented students $(\mathrm{M}=1.44, \mathrm{SD}=.52), p$ 
$<.002$; similarly, with active behavior $(\mathrm{M}=1.67, \mathrm{SD}=.57), p<.000$. But at the level of primary behavior students who have no experience to travel before is very low $(\mathrm{M}=1.67, \mathrm{SD}=.57), p<.000$. However, students with travel experience have higher emotive character $(\mathrm{M}=1.2, \mathrm{SD}=.44), p<.001$.

Finally, in the context of culture, it is bounced in this study that students who showed somehow similarity between the culture have also high active character $(\mathrm{M}=2, \mathrm{SD}=.63), p<.03$; seemingly, in primary character $(\mathrm{M}=1.75, \mathrm{SD}=.70)$, $p<.056$. However, students who proved no similarity showed great level of emotive behavior than others $(\mathrm{M}=1.44, \mathrm{SD}=.72), p<.001$; and active behavior $(\mathrm{M}=1.33, \mathrm{SD}=.57), p<.000$. Moreover, they also have the highest level of primary behavior $(\mathrm{M}=1.38, \mathrm{SD}=.74), p<.000$; and emotive character $(\mathrm{M}=1.4$, $\mathrm{SD}=.89), p<.001$.

\subsection{Correlational Result}

Through this result there is avowal that the different levels of education can be related with culture differences $r=.42, p<.003$. Then it is regarded that gender and marital status showed $\mathrm{r}=.26, p<.04$, so that means majority of the students are likely to have the same status. Then, gender is more correlated with emotive character $\mathrm{r}=.55, p<.000$. Besides, it is bounced in this study that the link between the emotional behavior state and age $r=-.47, p<.03$, and marital status $r$ $=.39, p<.008$. Then, it is found that the difference in religion is linked by the difference in continent $\mathrm{r}=.50, p<.00$. Therefore, the result ascribed that the relation is presented by matching active character to marital status $\mathrm{r}=.44, p$ $<.003$, and to emotive character $\mathrm{r}=.30, p<.03$. Similarly, with primary character $\mathrm{r}=.62, p<.000$; emotive behavior which has $\mathrm{r}=.48, p<.002$. Besides, it is recognized that the link between active behavior when emotional behavior presented $\mathrm{r}=.41, p<.005$. Considerably with emotional behavior, and primary behavior $\mathrm{r}=.50, p<.001$. However, relating primary character to the other variables, this study determined with age $\mathrm{r}-.56, p<.01$; marital status $.38, p<.01$; active behavior $\mathrm{r}=.54, p<.000$; emotive behavior $\mathrm{r}=69, p<.000$; and primary behavior $\mathrm{r}=.43, p<.003$. It noticed also the link between the activity emotional behavior state and the duration of living in China $\mathrm{r}=.34, p<.02$; emotive behavior $\mathrm{r}=.52, p<.000$; and primary behavior $\mathrm{r}=.47, p<.01$. Moreover, after analyzing the correlation of emotive behavior, it is linked with marital status $r=.39$, $p<.008$. Finally, primary character is also related to the emotive character $\mathrm{r}$ $=.39, p<.008$ (see Table 4 correlation and Figure 1 cross correlation of marital status and active behavior, Figure 2 cross correlation of primary character and emotive behavior).

\subsection{Result of the Regression Study}

Basing on the analytical result of predicting the effect of the age on the emotional behavior, it showed that the emotional behavior affect can negatively predicted by age $\beta=-.41, \mathrm{t}=-1.997, p<.06$; CI lower Bound $=-3.231$ and Upper Bound $=.115$. Besides, the significance prediction between marital status and 
Table 4. Correlations.

\begin{tabular}{|c|c|c|c|c|c|c|c|c|c|c|c|c|c|}
\hline & & gder & age & M S & Reg & Lev & Cont & dur & E ch & $\mathrm{P}$ ch & $\mathrm{Ab}$ & $\mathrm{Pb}$ & $\mathrm{E} \mathrm{b}$ \\
\hline \multirow{3}{*}{ Gender } & $\mathrm{r}$ & 1 & & & & & & & & & & & \\
\hline & Sig. & & & & & & & & & & & & \\
\hline & $\mathrm{N}$ & 42 & & & & & & & & & & & \\
\hline \multirow{3}{*}{ Age } & $\mathrm{r}$ & -.194 & 1 & & & & & & & & & & \\
\hline & Sig. & .472 & & & & & & & & & & & \\
\hline & $\mathrm{N}$ & 16 & 16 & & & & & & & & & & \\
\hline \multirow{3}{*}{$\begin{array}{c}\text { Marital } \\
\text { status }\end{array}$} & $\mathrm{r}$ & .268 & $-.609^{*}$ & 1 & & & & & & & & & \\
\hline & Sig. & .086 & .012 & & & & & & & & & & \\
\hline & $\mathrm{N}$ & 42 & 16 & 42 & & & & & & & & & \\
\hline \multirow{3}{*}{ Religion } & $\mathrm{r}$ & .166 & .020 & .063 & 1 & & & & & & & & \\
\hline & Sig. & .299 & .942 & .693 & & & & & & & & & \\
\hline & $\mathrm{N}$ & 41 & 16 & 41 & 41 & & & & & & & & \\
\hline \multirow{3}{*}{ Level } & $\mathrm{r}$ & -.183 & .473 & $-.315^{*}$ & .036 & 1 & & & & & & & \\
\hline & Sig. & .252 & .064 & .045 & .825 & & & & & & & & \\
\hline & $\mathrm{N}$ & 41 & 16 & 41 & 40 & 41 & & & & & & & \\
\hline \multirow{3}{*}{ Continent } & $\mathrm{r}$ & .114 & -.455 & -.045 & $.504^{\star *}$ & -.084 & 1 & & & & & & \\
\hline & Sig. & .471 & .077 & .779 & .001 & .600 & & & & & & & \\
\hline & $\mathrm{N}$ & 42 & 16 & 42 & 41 & 41 & 42 & & & & & & \\
\hline \multirow{3}{*}{ Duration } & $\mathrm{r}$ & -.132 & .122 & -.202 & -.052 & -.006 & .069 & 1 & & & & & \\
\hline & Sig. & .458 & .652 & .252 & .770 & .974 & .698 & & & & & & \\
\hline & $\mathrm{N}$ & 34 & 16 & 34 & 34 & 33 & 34 & 34 & & & & & \\
\hline \multirow{3}{*}{$\begin{array}{l}\text { Emotive } \\
\text { character }\end{array}$} & $\mathrm{r}$ & $.549^{\star *}$ & .066 & .202 & .149 & -.008 & -.082 & -.246 & 1 & & & & \\
\hline & Sig. & .000 & .816 & .230 & .384 & .964 & .630 & .183 & & & & & \\
\hline & $\mathrm{N}$ & 37 & 15 & 37 & 36 & 36 & 37 & 31 & 37 & & & & \\
\hline \multirow{3}{*}{$\begin{array}{l}\text { Primary } \\
\text { character }\end{array}$} & $\mathrm{r}$ & .098 & $-.561^{\star}$ & $.378^{*}$ & -.243 & -.225 & .015 & .008 & .158 & 1 & & & . \\
\hline & Sig. & .559 & .024 & .019 & .147 & .180 & .928 & .965 & .357 & & & & \\
\hline & $\mathrm{N}$ & 38 & 16 & 38 & 37 & 37 & 38 & 32 & 36 & 38 & & & \\
\hline \multirow{3}{*}{$\begin{array}{c}\text { Active } \\
\text { behavior }\end{array}$} & $\mathrm{r}$ & -.048 & .165 & .180 & -.189 & -.046 & -.142 & $.344^{\star}$ & .237 & $.548^{* *}$ & 1 & & \\
\hline & Sig. & .764 & .540 & .259 & .242 & .776 & .375 & .046 & .158 & .000 & & & \\
\hline & $\mathrm{N}$ & 41 & 16 & 41 & 40 & 40 & 41 & 34 & 37 & 38 & 41 & & \\
\hline \multirow{3}{*}{$\begin{array}{l}\text { Primary } \\
\text { behavior }\end{array}$} & $\mathrm{r}$ & .083 & -.118 & .131 & .107 & -.211 & .039 & .081 & $.394^{*}$ & $.435^{\star *}$ & $.470^{* *}$ & 1 & \\
\hline & Sig. & .605 & .663 & .413 & .510 & .191 & .807 & .650 & .016 & .006 & .002 & & \\
\hline & $\mathrm{N}$ & 41 & 16 & 41 & 40 & 40 & 41 & 34 & 37 & 38 & 41 & 41 & \\
\hline \multirow{3}{*}{$\begin{array}{l}\text { Emotive } \\
\text { behavior }\end{array}$} & $\mathrm{r}$ & .059 & -.471 & $.395^{\star}$ & -.182 & -.244 & .174 & .136 & .165 & $.691^{* *}$ & $.524^{\star *}$ & .141 & 1 \\
\hline & Sig. & .728 & .066 & .015 & .289 & .151 & .303 & .449 & .350 & .000 & .001 & .407 & \\
\hline & $\mathrm{N}$ & 37 & 16 & 37 & 36 & 36 & 37 & 33 & 34 & 35 & 37 & 37 & 37 \\
\hline
\end{tabular}

${ }^{*}$ Correlation is significant at the 0.05 level (2-tailed). ${ }^{*}$ Correlation is significant at the 0.01 level (2-tailed). 


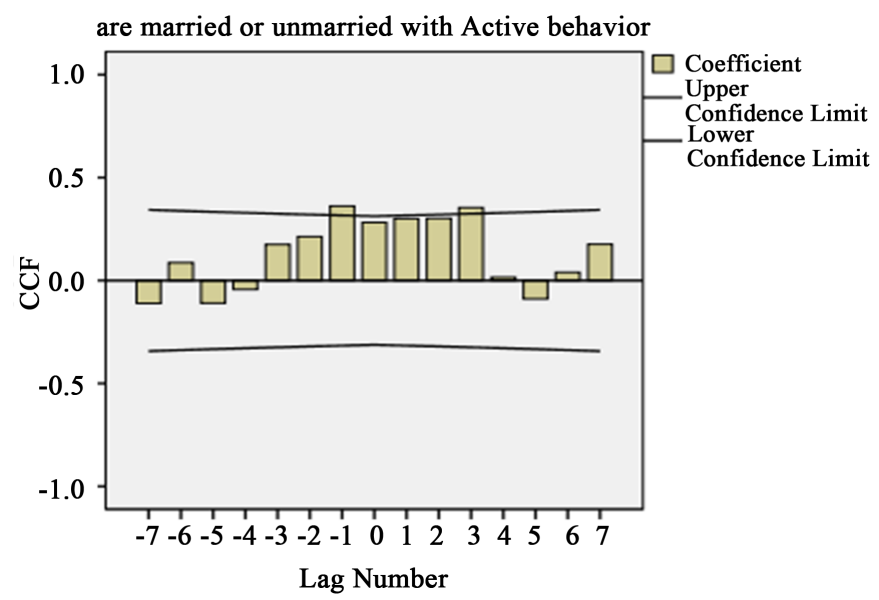

Figure 1. Cross-correlation frequency between marital status and active behavior.

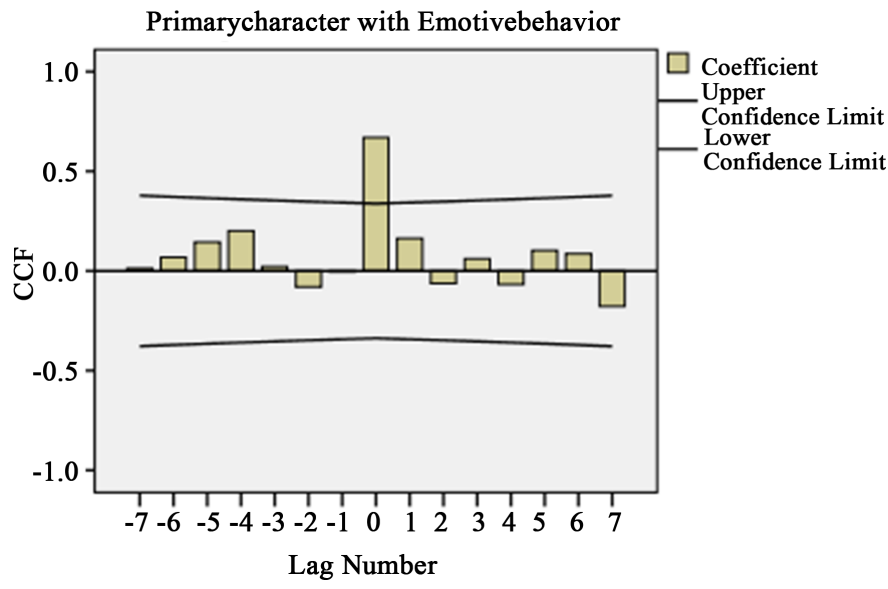

Figure 2. Cross-correlation frequency between primary character and emotive behavior

emotional behavior is positive but quiet small $\beta=.39, \mathrm{t}=2.546, p<.01$; CI Lower Bound $=.573$ and Upper Bound $=5.077$; because most of the participant are about to have the same status. Furthermore, there is a considerable effect of marital status on the active character $\beta=.436, \mathrm{t}=2.947, p<.006$; CI Lower Bound $=1.043$ and Upper Bound $=5.636$. Moreover, the result ascribed that age also can have its own impacts on the primary character negatively $\beta=-.561, \mathrm{t}=$ $-2.536, p$.024; CI Lower Bound $=-2.817$ and Upper $=-.236$. Then, the study predicted that the marital status has some effect on a person primary character positively $\mathrm{B}=.378, \mathrm{t}=2.448, p<.019$; $\mathrm{CI}$ Lower Bound $=.380$ and Upper $=$ 4.057. This result provided the positive prediction effect of duration of living in China on the emotional active behavior of students $\beta=.466, \mathrm{t}=2.074, p<.046$; CI Lower Bound $=.017$ and Upper Bound $=1.915$. Seemingly, emotive behavior is affected negatively by age $\beta=-.471, \mathrm{t}=-1.997, p<.06$; CI Lower Bound $=$ -3.231 and Upper $=.115$. But, basing on this result the emotional behavior is affected by marital status in positive manner $\beta=.395, \mathrm{t}=2.546, p<.01$; CI Lower Bound $=.573$ and Upper Bound $=5.077$ (see Figure 3 Regression of gender on emotive character and age on emotive behavior) (Figure 4). 


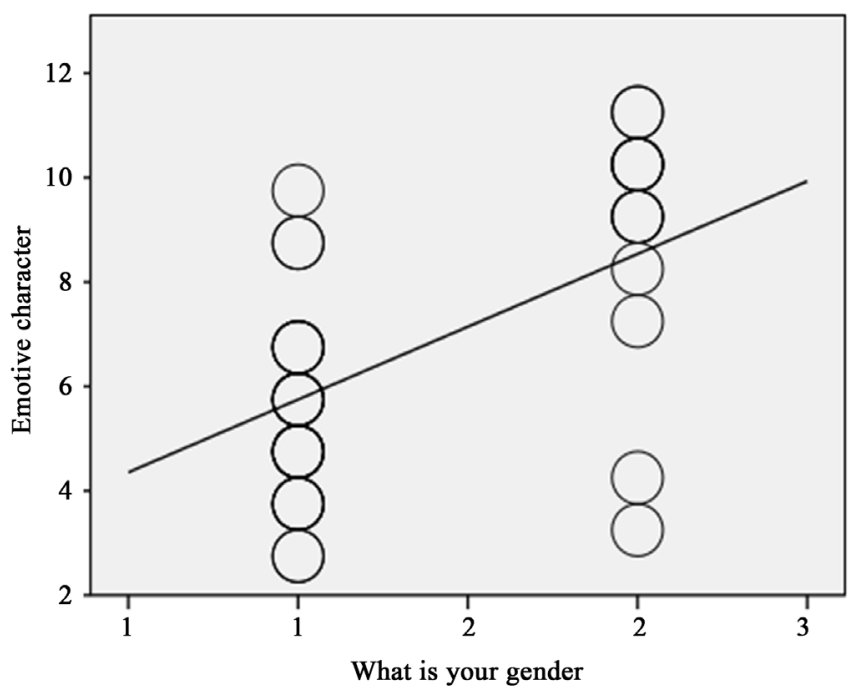

Figure 3. Prediction of gender on emotive character

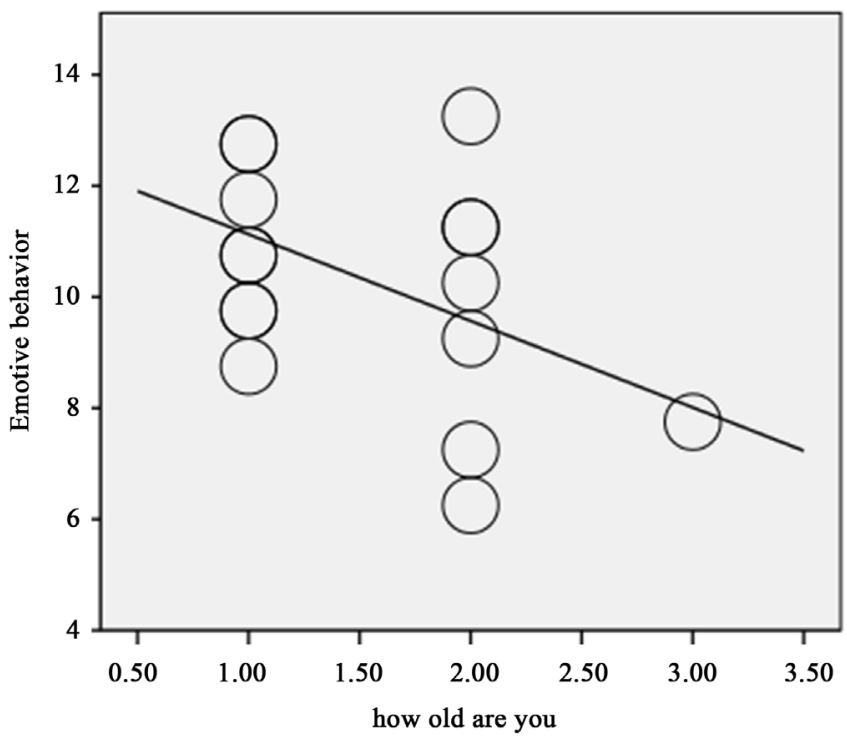

Figure 4. Predication of different groups of age on emotive behavior

\section{Discussion}

This study aimed to test the hypothesis according to which the adaptation in new situation of life would be predominantly predicted with interpretation of emotional characters and behaviors regarding the social context of individual. Therefore, the result showed that social dimension such as age, marital status, and duration to stay abroad are good predictor of emotional character and behavior interpretation.

Besides, this study used cross-sectional study instead of longitudinal one. And for gathering data, it includes only questionnaire without open-ending questions. Furthermore, the number of participants who took this study was small. Moreover, there was more bias in answering some variables especially age.

We can reject the null hypothesis which backed up the idea that intercultural 
exchange can affect student emotional behavior; such as evidences from the research of (Zongkui, et al, 2011) proved that subsequent psychosocial maladjustments, including externalizing and internalizing problems (such as feelings of loneliness and depression) children are facing social complexity: within individuals, within interactions, within relationships, and within groups. And then it contrasts with The study done by (Ngwira et al., 2015) which talked about Intercultural Communication Competence and Acculturation among International Students in Central China Normal University (CCNU). So, that research showed that Asian international students are less motivated to adapt than other students from other continents. In addition, time and education level do not seem to be sufficient factors in facilitating adaptation. Indeed, focusing on this result, aged people are suffering more in emotional state to adapt themselves.

Consistently, we support the alternative hypothesis that emphasis on the fact that people from the different societal dimensions or categories will have different way to adapt themselves to the new condition of life. Like in the result of the correlational avowed that the different levels of education can be related with culture differences positively. So that can show us people from the same culture are closely at the same level of study. In that way, it is supporting Franz boas' ideology of cultural relativism, in which he said that all humans see the world through the lens of their own culture, and judge it according to their own culturally acquired norms. Then the study done by Yang \& Chang (2014), shows that resilience is the main attractive in culture adaptation.

\section{Conclusion}

In sum, basing on the result of this research which focused on the adaptation problem in psycho-sociological dimensions such as emotional character and behavior regulation with the social status, the study proposed that with difference in age, with the difference in marital status, with the difference in duration to stay abroad, people cannot have the same manner to feel themselves in the new place.

Therefore, through this finding, a new research which can be proposed for future is to conduct a study including interview and open-ending questions and focusing on the person of different ages. So that will help us to clarify which specific problems are relevant to their emotional state when they are studying abroad. Moreover, we proposed for new research to have the focus on not only the effect of age on the emotional state but to bounce out the direction in which age can affect the emotional state of international students such negatively or positively. Indeed, age appears as an important indicator to identify the quality of inter-cultural exchange effect. This study is limited by its cross-sectional character, and its size of sampling.

\section{Conflicts of Interest}

The authors declare no conflicts of interest regarding the publication of this paper. 


\section{References}

Hatfield, et.al. (1994). Emotional Contagion. Cambridge: Cambridge University Press.

Kakabadse, K. N., Korac-Kakabadse, A., \& Kouzmin, A. (1998). The Role of IT in Changing Psycho-Social Contracts: A Multi-Stakeholder's Perspective. Knowledge and Process Management, 5, 132-140. https://doi.org/10.1002/(SICI)1099-1441(199806)5:2<132::AID-KPM16>3.0.CO;2-C

Mayer, J. D., \& Salovey, P. (1995) Emotional Intelligence and the Construction and Regulation of Feelings. Applied \& Preventive Psychology, 4, 197-208.

https://doi.org/10.1016/S0962-1849(05)80058-7

Nansook, P., Peterson, C., \& Seligman, M. E. P. (2004). Strengths of Character and Well-Being. Journal of Social and Clinical Psychology, 23, 603-619. https://doi.org/10.1521/jscp.23.5.603.50748

Shumate-Fowler, A. M. (1995). The Psychological Aspects of Travel Abroad. University of Tennessee Honors, Thesis Projects. https://trace.tennessee.edu/utk chanhonoproj/114

Yang, H. F., \& Chang, E. C. (2014). Examining the Structure, Reliability, and Validity of the Chinese Personal Growth Initiative Scale-II: Evidence for the Importance of Intentional Self-Change Among Chinese. Journal of Personality Assessment, 96, 559-566 https://doi.org/10.1080/00223891.2014.886256

Zheutlin, S., \& Goldstein, S. G. (1977). The Prediction of Psycho-Social Adjustment Subsequent to Cardiac Insult. Journal of Clinical Psychology, 33. https://doi.org/10.1002/1097-4679(197707)33:3<706::AID-JCLP2270330320>3.0.CO;2$\underline{6}$ 